\title{
Incidence of complications of SMall Incision Lenticule Extraction (SMILE)
}

\section{Incidencia de complicaciones de la cirugía de extracción del lentículo por incisión pequeña (SMILE)}

\author{
Samuel J. Avalos-Lara*, Cristina Pacheco-del Valle, Oscar Baca-Lozada, Elisa D. Alegría-Gómez, \\ Oscar Fernández-Vizcaya and Regina Velasco-Ramos \\ Department of cornea and refractive surgery, Fundación Hospital Nuestra Señora de la Luz, IAP, Mexico City, Mexico
}

\begin{abstract}
Purpose: To summarize the complications and their incidence in the learning curve of the "small incision lenticule extraction (SMILE)"surgical technique. Material and methods: Prospective, descriptive and observational study. We evaluated the intraoperative and postoperative complications of patients undergoing SMILE refractive surgery with femtosecond laser from January 2015 to January 2018 at the Hospital Nuestra Señora de la Luz, Mexico. The platform used for surgery was the VisuMax by Zeiss. Statistical analysis was performed with Excel. Results: 526 eyes of 263 patients undergoing "SMILE" refractive surgery were studied. Intraoperative complications were observed in 70 of 526 eyes. The main complication was difficult lenticule extraction in 27 eyes (5.13\%), epithelial abrasion in 15 eyes (2.85\%), incision tear 12 in eyes (2.28\%), lost vacuum in 7 eyes (1.33\%), incomplete lenticule removal in 4 eyes (0.76\%), black spot in 4 eyes (0.76\%) and wound bleeding in 1 eye (0.19\%). All complications were resolved intraoperatively. Conclusions: SMILE surgical technique is safe, showing excellent results in final visual acuity.
\end{abstract}

Key words: Refractive surgery. Small incision lenticule extraction. Complications.

\section{Resumen}

Objetivo: Conocer las complicaciones y la incidencia en la curva de aprendizaje de la técnica quirúrgica de extracción del lentículo por incisión pequeña (SMILE). Material and methods: Estudio prospectivo, descriptivo y observacional. Se estudiaron las complicaciones intraoperatorias y postoperatorias de los pacientes sometidos a cirugía refractiva con la técnica quirúrgica de SMILE por femtosegundo, de enero de 2015 a enero de 2018, en la Fundación Hospital Nuestra Señora de la Luz. Para la cirugía se utilizó la plataforma VisuMax ${ }^{\circledR}$ de Zeiss ${ }^{\circledR}$. Se realizó el análisis estadístico en la plataforma Excel. Resultados: Se estudiaron 526 ojos de 263 pacientes sometidos a cirugía refractiva con técnica quirúrgica SMILE. Las complicaciones transoperatorias se observaron en 70 de los 526 ojos. La principal complicación fue dificultad para extraer el lentículo, 27 ojos (5.13\%), seguido de abrasión epitelial, 15 ojos (2.85\%), desgarro de la incisión, 12 ojos (2.28\%), pérdida de la succión, 7 ojos (1.33\%), ruptura del lentículo, 4 ojos (0.76\%), black spot, 4 ojos (0.76\%) y hemorragia en interfase, 1 ojo (0.19\%). Todas las complicaciones se resolvieron de manera transoperatoria. Conclusiones: La técnica quirúrgica SMI$L E$ es segura, con excelentes resultados en la agudeza visual final.

Palabras clave: Cirugía refractiva. SMILE. Complicaciones.

\section{Correspondence:}

*Samuel J. Avalos-Lara

Ezequiel Montes, 135

Col. Tabacalera, Del. Alcaldía Cuauhtémoc Date of reception: 28-06-2018 C.P. 06030, Mexico City, Mexico

E-mail: josue.27al@gmail.com DOI: 10.24875/RMOE.M20000100 Date of acceptance: 16-12-2019 (http://creativecommons.org/licenses/by-nc-nd/4.0/).

Available online: 01-03-2020 Rev Mex Oftalmol (Eng). 2020;94(2):71-76 www.rmo.com.mx 


\section{Introduction}

Refractive surgery is an elective surgery through which patients seek to improve their vision ${ }^{1}$. Small incision lenticule extraction (SMILE) consists on creating a lenticule within an intact cornea, and then removing it through a small incision, typically less than $4 \mathrm{~mm}$ in size $^{2}$.

SMILE offers the advantage that it does not require a flap, so it creates minimal disruption of the architecture of the anterior stroma ${ }^{3}$.

This procedure requires the VisuMax ${ }^{\circledR}$ femtosecond laser (Carl Zeiss Meditec, Jena, Germany), which was introduced in $2007^{4}$. The posterior interface of the lenticular stroma is first created from the periphery to the center (out-to-in), followed by the anterior interface of the lenticule, from the center to the periphery (in-to-out). Finally, an incision of 2 to $4 \mathrm{~mm}$ is made usually in the upper-temporal quadrant. Subsequently, under the microscope, the lenticule is separated and extracted ${ }^{5}$.

There are very few studies that reported complications related to SMILE surgery. Ivarsen, et al. conducted a study where 1,800 SMILE procedures were performed. The most frequent intraoperative complications were epithelial abrasions, difficult lenticule extraction and small incision tears, while the most frequent postoperative complications were corneal haze, interface inflammation and corneal topography irregularity ${ }^{6}$. Being a technique that only affects the posterior stroma, there is a greater preservation of the corneal subbasal nerve plexus, which reduces the risk of dry eye as a long-term postoperative complication ${ }^{7}$. Another reported complication is residual lenticule that produces irregular astigmatism, which can be effectively treated using phototherapeutic epithelial keratectomy (PTK) 8,9 .

SMILE is currently indicated in patients with myopia of up to -10.00 diopters with cylindrical errors of up to -6.00 diopters $^{10}$. However, this surgery has shown that there are no significant changes in the spherical equivalent after 5 years of follow-up ${ }^{11}$. SMILE has shown almost identical results to those obtained with LASIK (Laser Assisted in Situ Keratomileusis) $^{12}$.

\section{Objective}

The objective of this study is to assess intraoperative and postoperative complications in patients undergoing elective SMILE refractive surgery, as well as its incidence. Also, to compare the incidence of intraoperative and postoperative complications in the Fundación Hospital Nuestra Señora de la Luz with that of the literature.

\section{Methods}

A prospective, descriptive and longitudinal study was carried out. Intraoperative and postoperative complications of patients undergoing femtosecond-based SMILE refractive surgery from January 2015 to January 2018, were studied in the Department of Cornea and Refractive Surgery of the Fundación Hospital Nuestra Señora de la Luz. The platform for surgery used was VisuMax ${ }^{\circledR}$ by Zeiss ${ }^{\circledR}$. Patients enrolled were older than 18 years of age, without ocular pathology, normal corneal topography, corneal thickness greater than 500 microns and with a simple myopic refractive defect or compound myopic astigmatism. The surgical technique was performed with topical anesthesia, creating a $6.5 \mathrm{~mm}$ diameter lenticule at a depth of 120 microns and with a $4 \mathrm{~mm}$ corneal incision. The lenticule was dissected and subsequently removed, followed by irrigation with balanced salt solution to extract debris and finalizing with antibiotic $(0.3 \%$ gatifloxacin) and anti-steroidal inflammatory ( $1 \%$ prednisolone) application. The incidence of complications presented during three consecutive years was compared with that reported in the literature.

\section{Results}

The study included 526 eyes of 263 patients. Intraoperative complications were observed in 70 of the 526 eyes. The main complication was difficult lenticule extraction, 27 eyes $(5.13 \%)$, followed by epithelial abrasion, 15 eyes $(2.85 \%)$, incision tear, 12 eyes $(2.28 \%)$, suction loss, 7 eyes $(1.33 \%)$, lenticule rupture, 4 eyes $(0.76 \%)$, black spot, 4 eyes $(0.76 \%)$ and interface bleeding, 1 eye $(0.19 \%)$ (Table 1 and Fig. 1$)$. All complications were resolved intraoperatively. As for the patients with suction loss, in two of them an incision was made manually, in the remaining 5 eyes refractive surgery was rescheduled 3 months later.

In 122 eyes, postoperative findings were demonstrated by biomicroscopy from day 1 to day 7 . The most frequent was the presence of detritus, 61 eyes $(11.59 \%)$, superficial punctate keratopathy, 27 eyes $(5.13 \%)$, diffuse lamellar keratitis, 9 eyes (1.71\%), epithelial defect and corneal haze, 8 eyes (1.52\%), interface edema, 4 eyes $(0.76 \%)$, incision folds, 2 eyes $(0.38 \%)$, nummular deposits, epithelial growth and lenticule in interface, one case each $(0.19 \%)$ (Table 2$)$.

Tables 3 and 4 summarize the intraoperative and postoperative complications, respectively, observed in different references, including the incidence of complications in our hospital. 
Table 1. Intraoperative complications with the incidence percentage according to the number of complications ( $n$ ) and the percentage $(\%)$ from all cases

\begin{tabular}{|l|l|l|}
\hline Complications, $(\mathbf{n}=526)$ & n & $\%$ \\
\hline Difficult lenticule extraction & 27 & $5.13 \%$ \\
\hline Epithelial abrasion & 15 & $2.85 \%$ \\
\hline Incision tear & 12 & $2.28 \%$ \\
\hline Suction loss & 7 & $1.33 \%$ \\
\hline Lenticule rupture & 4 & $0.76 \%$ \\
\hline Black spot & 4 & $0.76 \%$ \\
\hline Interface hemorrhage & 1 & $0.19 \%$ \\
\hline
\end{tabular}

Table 2. Postoperative complications with the incidence percentage according to the number of complications ( $n$ ) and the percentage $(\%)$ from all cases

\begin{tabular}{|l|c|c|}
\hline Complications, $(\mathrm{n}=526)$ & $n$ & $\%$ \\
\hline Detritus & 61 & $11.59 \%$ \\
\hline Punctate superficial keratopathy & 27 & $5.13 \%$ \\
\hline Diffuse lamellar keratitis & 9 & $1.71 \%$ \\
\hline Epithelial defect & 8 & $1.52 \%$ \\
\hline Haze & 8 & $1.52 \%$ \\
\hline Interface edema & 4 & $0.76 \%$ \\
\hline Incision folds & 2 & $0.38 \%$ \\
\hline Nummular deposits & 1 & $0.19 \%$ \\
\hline Epithelial growth & 1 & $0.19 \%$ \\
\hline Lenticule interface & 1 & $0.19 \%$ \\
\hline
\end{tabular}

The final visual results were obtained with a 2-year follow-up in 204 eyes and with a 1-year follow-up in 322 eyes. Final visual acuities were divided into the following groups: group 1 = better than 20/40; group $2=20 / 50$ 20/100; group $3=$ worse than 20/100.

It was observed that 524 eyes from $526(99.61 \%)$ that underwent SMILE belonged to group 1. Of these, 54 eyes had a final visual acuity of $20 / 15 ; 373$ eyes of 20/20; 65 eyes, 20/25; 22 eyes, 20/30, and only 7 eyes, 20/40.

In group 2, only 2 eyes of $526(0.38 \%)$ had a final visual acuity of $20 / 50$ and $20 / 80$, respectively. In the eye with a visual acuity of $20 / 50$, there was a subcorrection of -0.75 sphere with +1.00 cylinder at $135^{\circ}$. In

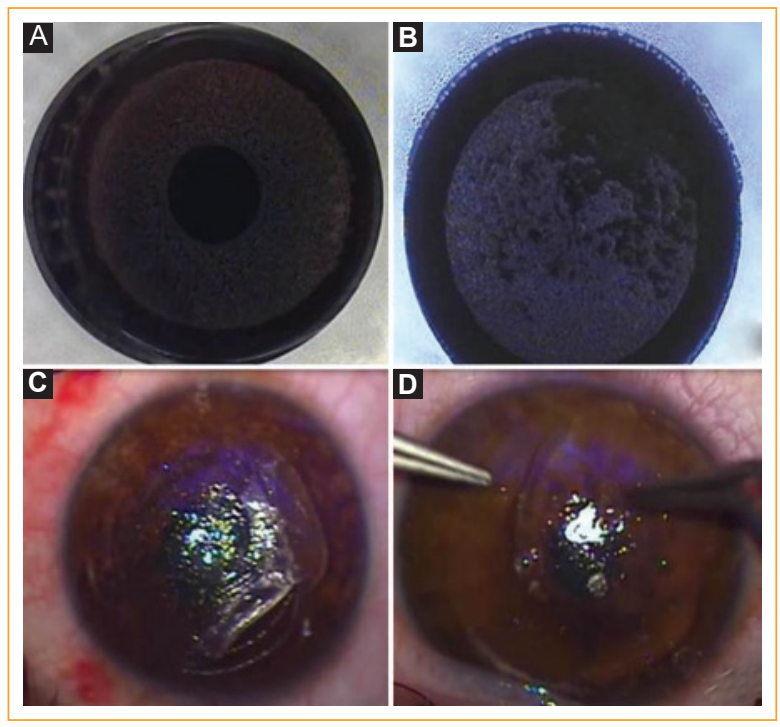

Figure 1. A: Black spot. B: Suction loss. C: Incision tear. D: Incomplete lenticule.

the eye with $20 / 80$, the patient had a history of anisometropic amblyopia.

None of the eyes that underwent SMILE were included in group 3 (Table 5).

\section{Discussion}

Despite being one of the studies with more eyes included (3,004 eyes), Wang, et al. reported a very low incidence of intraoperative complications, probably because the surgeries were performed by a single experienced surgeon, unlike our institution where ophthalmologists in training also perform this type of procedure $^{13}$. Suction loss occurred in 28 cases $(0.93 \%)$, and was more frequent during the creation of the anterior plane. The incidence may increase due to the level of anxiety of the patient ${ }^{14}$.

In other series, the incidence of suction loss with SMILE is from 2.1 to $4.4 \%$. Its incidence decreases with increased surgeon experience in this technique ${ }^{14,15}$. It can occur as a result of various factors, such as sudden eye movements, eyelid force during laser application, fluid entering between the contact lens and the cornea, gas migration and compressive forces against the contact lens.

Ivarsen, et al (2014) reported as the most frequent intraoperative complication epithelial abrasion (6\%), difficult lenticule extraction (1.9\%) and incision tear $(1.8 \%)^{16}$. In our study, the most frequent intraoperative complications were, first, difficult lenticule extraction 
Rev Mex Oftalmol (Eng). 2020;94(2)

Table 3. Intraoperative complications of SMILE refractive surgery compared to the literature

\begin{tabular}{|c|c|c|c|c|c|c|c|}
\hline & $\begin{array}{l}\text { Hospital } \\
\text { de la Luz } \\
\text { (526 } \\
\text { eyes) }\end{array}$ & $\begin{array}{c}\text { lvarsen, } \\
\text { et al. }{ }^{6} \\
\text { (1,574 } \\
\text { eyes) }\end{array}$ & $\begin{array}{c}\text { Ramírez, } \\
\text { et al. }{ }^{17} \\
\text { (160 } \\
\text { eyes) }\end{array}$ & $\begin{array}{c}\text { Chee, } \\
\text { et al. }{ }^{14} \\
\text { (340 } \\
\text { eyes) }\end{array}$ & $\begin{array}{l}\text { Osman, } \\
\text { ot al. }{ }^{15} \\
(3,376 \\
\text { eyes) }\end{array}$ & $\begin{array}{l}\text { Wang, } \\
\text { ot al. }{ }^{13} \\
\text { (3,004 } \\
\text { eyes) }\end{array}$ & $\begin{array}{c}\text { Chansue, } \\
\text { et al. }{ }^{2} \\
\text { (347 } \\
\text { eyes) }\end{array}$ \\
\hline Difficult lenticule extraction & $5.13 \%$ & $1.9 \%$ & - & - & - & - & - \\
\hline Incision tears & $2.28 \%$ & $1.8 \%$ & $16.2 \%$ & - & - & $0.17 \%$ & - \\
\hline Epithelial abrasions & $2.85 \%$ & $6 \%$ & - & - & - & - & - \\
\hline Suction loss & $1.33 \%$ & $0.8 \%$ & $11.6 \%$ & $4.4 \%$ & $2.1 \%$ & $0.93 \%$ & - \\
\hline Black spot & $0.76 \%$ & - & $14 \%$ & - & - & $0.33 \%$ & - \\
\hline Lenticule rupture & $0.76 \%$ & - & - & - & - & $0.27 \%$ & - \\
\hline Interface hemorrhage & $0.19 \%$ & - & - & - & - & $0.93 \%$ & - \\
\hline Perforation of the anterior aspect of the cornea & - & $0.22 \%$ & - & - & - & - & - \\
\hline Opaque bubble layer that prevents incision & - & - & $16.2 \%$ & - & - & $1.73 \%$ & - \\
\hline
\end{tabular}

Table 4. Postoperative complications of SMILE refractive surgery compared to the literature

\begin{tabular}{|c|c|c|c|c|c|}
\hline & $\begin{array}{l}\text { Hospital de la Luz } \\
\text { (526 eyes) }\end{array}$ & $\begin{array}{l}\text { Ivarsen, et al. }{ }^{6} \\
\text { (1,574 eyes) }\end{array}$ & $\begin{array}{l}\text { Ramírez, et al. }{ }^{17} \\
\text { (160 eyes) }\end{array}$ & $\begin{array}{l}\text { Zhao, et al. }{ }^{20} \\
\text { (1,112 eyes) }\end{array}$ & $\begin{array}{l}\text { Oiu, et al. }{ }^{22} \\
\text { (193 eyes) }\end{array}$ \\
\hline Detritus & $11.59 \%$ & - & - & - & - \\
\hline Punctate superficial keratopathy & $5.13 \%$ & - & - & - & - \\
\hline Corneal haze & $1.52 \%$ & $8 \%$ & - & - & - \\
\hline Epithelial defect & $1.52 \%$ & - & $41.9 \%$ & - & - \\
\hline Tear film dysfunction & - & $5 \%$ & - & - & $54 \%$ \\
\hline Interface edema & $0.76 \%$ & $0.3 \%$ & - & - & - \\
\hline Diffuse lamellar keratitis & $1.71 \%$ & - & - & $1.6 \%$ & - \\
\hline Residual lenticule & $0.19 \%$ & - & - & - & - \\
\hline
\end{tabular}

SMILE: small-incision lenticule extraction.

(5.13\%), followed by epithelial abrasion $(2.85 \%)$ and incision tear $(2.28 \%)$. This difference is probably explained by the learning curve of this new surgical technique, since we have been doing it only for 4 years.

Another ophthalmological center in Mexico (Ramírez, et al, 2015) reported a higher incidence of complications, and the most frequent were epithelial defect $(41.9 \%)$, incision tear $(16.2 \%)$ and black spot $(14 \%)^{17}$. At the Hospital de la Luz, the incidence is not correlated, with a lower incidence of epithelial defects $(1.52 \%)$, incision tear $(2.28 \%)$ and black spot $(0.76 \%)$. Despite having a high incidence of epithelial defects, it is a transitory complication that does not affect visual acuity. Probably our institution has a lower incidence of incision tear because we make a slightly larger incision for lenticule extraction.

Most of the intraoperative complications are due to the surgeon's inexperience to identify the lenticule's edge. This forces the surgeon to continue trying to dissect under or over the lenticule for a prolonged period, which leads to an increase in the possibility of complications such as incision or lenticule tear, as well as longer operation times. The appropriate recognition of the lenticule edge facilitates surgery due to the rapid recognition of the lenticule with its anterior and posterior surfaces, thus shortening the average duration of the surgery and minimizing intraoperative complications $^{18}$. 
Table 5. Final visual acuity of patients undergoing SMILE surgery with 2- and 1-year follow-up

\begin{tabular}{|l|c|c|}
\hline Group & Final visual acuity & $n(\%)$ \\
\hline $\begin{array}{l}\text { Group } 1 \\
\text { Better than 20/40 } \\
(99.61 \%)\end{array}$ & $20 / 15$ & $54(10.26)$ \\
\hline & $20 / 20$ & $373(70.91)$ \\
\hline $\begin{array}{l}\text { Group 2 } \\
20 / 50-20 / 100 \\
(0.38 \%)\end{array}$ & $65(12.35)$ \\
\hline $\begin{array}{l}\text { Group 3 } \\
\text { Worse than 20/100 } \\
\text { (0\%) }\end{array}$ & $20 / 30$ & $7(1.33)$ \\
\hline \begin{tabular}{l} 
SMILE: small-incision lenticule extraction. \\
\hline
\end{tabular} & $20 / 50$ & $1(0.19)$ \\
\hline
\end{tabular}

The most frequent postoperative complications were detritus (11.59\%), superficial punctate keratopathy $(5.13 \%)$, epithelial defects and haze (1.52\%). Ivarsen, et al. reported corneal haze as the most frequent postoperative complication (8\%). Postoperative complications are published to a much lesser extent than intraoperative ones. Most authors do not consider detritus as a postoperative complication, since it does not affect visual acuity.

Residual lenticule occurred only in 1 patient $(0.19 \%)$. We found only a published case reporting a residual lenticule by optical coherence tomography (OCT) 5 months after surgery. The patient had a visual loss of 3 lines one month after surgery and, subsequently, a visual improvement of 2 lines five months after surgery ${ }^{19}$.

Diffuse lamellar keratitis was initially described as an early complication with LASIK, with an incidence of 0.13 to $18.9 \%^{20}$. The study by Zhao, et al. included 1,112 eyes of 590 patients, and 18 eyes of 11 patients developed diffuse lamellar keratitis, with an incidence of $1.6 \%$. In $77.8 \%$ of cases it was bilateral and in $22.2 \%$ it was unilateral. The incidence is associated with a larger lenticule diameter and thinner lenticules, resulting in a thicker residual stromal base ${ }^{21}$. In our case, the incidence was discretely higher (3.99\%), and we cannot associate it with changes in the lenticule diameter, since all the patients who underwent the procedure had the same lenticule diameter. Of the patients who experienced this complication, only one underwent interface wash in the postoperative period due to a stage 3 , that was subsequently managed with a topical steroid. The final visual acuity of thise case was 20/25. All other cases of diffuse lamellar keratitis were stage 1 and 2, managed only with topical steroids, and had better final visual acuities of 20/25.

Although SMILE is performed without the creation of a flap, and theoretically the anatomical and biomechanical structure of the cornea is maintained, some patients have dry eye symptoms. Qiu, et al. reported that $54 \%$ of patients undergoing SMILE have dry eye symptoms 1 week after surgery; however, 3 months after surgery, the symptoms decreased to almost the same level as in the preoperative period ${ }^{22}$. In this study, tear film function was not studied.

Opaque bubble layers did not occur in our patients; however, Wang, et al. reported an incidence of $0.73 \%$. They can make surgery difficult due to inadequate visualization of lenticule dissection, complicating its extraction, or even preventing it ${ }^{13}$.

There were no infectious complications in our hospital; there are case reports showing interstitial keratitis due to Streptococcus pneumoniae in both eyes ${ }^{23}$. To the best of our knowledge, there is no reported incidence of infectious keratitis after SMILE in the literature; however, compared to other techniques, the incidence reported after LASIK is only of $0.03 \%{ }^{24}$.

Detritus is not reported as a postoperative complication in any of the series published in the literature. It is considered a postoperative finding that does not affect the final result of the refractive procedure. If we do not consider detritus a postoperative complication, then the percentage of postoperative complications is only of $13.11 \%$, with superficial punctate keratopathy in the first place, which can be effectively managed with ocular lubricants.

From the patients undergoing refractive SMILE surgery, $99.61 \%$ had a visual acuity better than 20/40, regardless of the presence of intraoperative or postoperative complications. None of the patients had a visual acuity worse than 20/100. Fortunately, most complications can be resolved during surgery, without affecting final visual acuity. Han, et al. reported that after a 4-year follow-up of patients undergoing SMILE, $92 \%$ of patients had an uncorrected visual acuity better or equal to $20 / 20^{25}$. In our study, $81.17 \%$ had an uncorrected visual acuity better than or equal to 20/20.

\section{Conclusion}

Refractive surgery is constantly evolving in the field of ophthalmology. Patients choose this surgical treatment 
with increased frequency due to the cost of eyeglasses and contact lenses, in addition to facial aesthetics and advantages of being spectacle-free. Currently there are different surgical techniques, including LASIK, PRK, femto-LASIK, phakic intraocular lenses and SMILE.

The incidence of intraoperative and postoperative complications with SMILE is relatively low, and they can be resolved without an impact on final visual acuity. The incidence observed in our hospital does not correlate to that of other hospitals in other parts of the world.

More reports of complications on this new surgical technique should be published, since although it is known that it has adequate safety and predictability rates, surgical complications can happen. In addition, there are few studies that specify the possible complications that occur with SMILE surgery.

\section{Limitations}

The limitations of this study are that it is a descriptive study. The surgeries were performed by different ophthalmologists in training and not just by one experienced surgeon. The surgical technique varies slightly between the studies published in the literature.

\section{Conflicts of interest}

The authors declare no conflicts of interest.

\section{Ethical disclosures}

Authorization number of the ethics committee, 2016 CR1.

Protection of human and animal subjects. The authors declare that no experiments were performed on humans or animals for this study.

Confidentiality of data. The authors declare that they have followed the protocols of their Institution

on the publication of patient data.

Right to privacy and informed consent. The authors declare that no patient data appear in this article.

\section{References}

1. Mysore N, Krueger R. Advances in Refractive Surgery May 2013 to June 2014. Asia Pac J Ophtalmol. 2015;4:2:112-20.

2. Chansue E, Tanehsakdi M, Swasdibutra S, McAlinden C. Efficacy, predictability and safety of small incisión lenticule extraction (SMILE). Eye Vis. 2015;2:14.

3. Aristeidou A, Taniguchi EV, Tsatsos M, Muller R, McAlinden C, Pineda R, et al. The evolution of corneal and refractive surgery with the femtosecond laser. Eye Vis. 2015;2:12.

4. Reinstein DZ, Archer TJ, Gobbe M, Johnson N. Accuracy and reproducibility of Artemis central flap thickness and visual outcomes of LASIK with the Carl zeiss meditec VisuMax femtosecond laser and MEL 80 excimer laser platforms. J Refract Surg. 2010;26:107-19.

5. Reinstein DR, Archer TJ, Gobbe M. Small incision lenticule extraction (SMILE) history, fundamentals of a new refractive surgery technique and clinical outcomes. Eye Vis. 2014;1:3.

6. Ivarsen A, Asp S, Hjortdal J. Safety and Complications of More Than 1500 small incision lenticule extraction procedures. Am Acad Ophtalmol. 2014;121:4.

7. Wang B, Naidu RK, Chu R, Dai J, Qu X, Zhou H. Dry eye disease following refractive surgery: A 12-month follow-up of SMILE versus FS-LASIK in high myopia. J Ophtalmol. 2015; 2015:132417.

8. Dong Z, Zhou X. Irregular astigmatism after femtosecond laser refractive Ienticule extraction. J Cataract Refract Surg. 2013;39:952-4.

9. Reinstein DZ, Archer TJ, Dickeson ZI, Gobbe M. Trans-epithelial phototherapeutic keratectomy protocol for treating irregular astigmatism based population on epithelial thickness measurements by Artemis very high-frequency digital ultrasound. J Refract Surg. 2014;30:380-7.

10. Ekktet Chansue, Morakot Tenehsakdi, Sukanda Swasdibutra, Colm McAlinden. Safety and efficacy of VisuMax circle patterns for flap creation and enhancement following small incision lenticule extraction. Eye Vis. 2015;2:21.

11. Marcus Blum, Kathrin Täubig, Christin Gruhn, Walter Sekundo, Kathleen $\mathrm{S}$ Skunert. Five-year results of small incision lenticule extraction (SMILE). Ophtalmol. 2016:0:1-4

12. Moshirfar M, McCaughey MV, Reinstein DZ, Shah R, Santiago-Caban L, Fenzl CR. Small-incision lenticule extraction. Cataract Refract Surg. 2015;41:652-65.

13. Wang $\mathrm{Y}$, Ma J, Zhang J, Dou R, Zhang H, Li L, et al. Incidence and management of intraoperative complications during small-incision lenticule extraction in 3004 cases. J Cataract Refract Surg. 2017;43(6):796-802.

14. Wong CW, Chan C, Tan D, Mehta JS. Incidence and management of suction loss in refractive lenticule extraction. J Cataract Refract Surg. 2014;40(12):2002-10.

15. Osman IM, Awad R, Shi W, Abou Shousha M. Suction loss during femtosecond laser-assisted small-incision lenticule extraction: Incidence and analysis of risk factors. J Cataract Refract Surg. 2016;42:246-50.

16. Ivarsen A, Sven A, Hjortdal J. Safety and Complications of More Than 1500 small incision lenticule extraction procedures. Ophtalmology. 2014:121:4.

17. Ramirez-Miranda A, Ramirez-Luquin T, Navas A, Graue-Hernández EO. Refractive Lenticule Extraction Complications. Cornea. 2015;34(Suppl):S65-7.

18. Hamed AM, Abdelwahab SM, Soliman TT. Intraoperative complications of refractive small incision lenticule extraction in the early learning curve. Clin Ophthalmol. 2018;12:665-8.

19. Dong Z, Zhou X. Irregular astigmatism after femtosecond laser refractive Ienticule extraction. J Cataract Refract Surg. 2013;39:952-4.

20. Zhao J, He L, Yao P, Shen Y, Zhou Z, Miao H, et al. Diffuse lamellar keratitis after small-incision lenticule extraction. J Cataract Refract Surg. 2015;41:400-7

21. Gritz DC. LASIK interface keratitis: epidemiology, diagnosis and care. Curr Opin Ophtalmol. 2011;22:251-5.

22. Qiu PJ, Yang YB. Early changes to dry eye and ocularsurface after smaII-incision lenticule extraction for myopia. Int J Ophtalmol. 2016;9:575-9.

23. Chehaibou I, Sandali O, Ameline B, Bouheraoua N, Borderie V, Laroche L. Bilateral infectious keratitis after small-incision lenticule extraction. J Cataract Refract Surg. 2016;42:626-30.

24. Llovet F, de Rojas V, Interlandi E, Martin C, Cobo-Soriano R, Ortega-Usobiaga J, et al. Infectious keratitis in 204,586 LASIK procedures. Ophtalmology. 2010;117:232-238.e1-4.

25. Han T, Zheng K, Chen Y, Gao Y, He L, Zhou X. Four-year observation of predictability and stability of small incision lenticule extraction. Ophthalmology. 2016;16:149 